\title{
Preface - The critical seventh year
}

\author{
T. Czigány*
}

Department of Polymer Engineering, Faculty of Mechanical Engineering, Budapest University of Technology and Economics, Müegyetem rkp. 3., H-1111, Budapest, Hungary

\section{Dear Readers,}

eXPRESS Polymer Letters has started its seventh volume. Even though seven is a lucky number, the seventh year in any relationship is often considered a critical one, as many things may appear usual, boring and worn-out by then. I strongly believe that eXPRESS Polymer Letters will maintain its good relationship with its readers, who will find new, interesting and useful articles in every issue of the seventh volume as well. I also hope that eXPRESS Polymer Letters will continue having a good relationship with its authors, too, and will receive plenty of 'cutting-edge' articles in 2013 just like in the previous years, even though the rejection rate has reached over $80 \%$ by now. Finally, I build upon our referees' continuing professional reviewing work that has lead to the ever growing impact factor and recognition of $\boldsymbol{e X P R E S S}$ Polymer Letters so far. The journal has got its first impact factor of 1.452 by 2009 , which was only its third year, and it was raised to 1.575 in 2010 and to 1.769 in 2011. Our short term goal is to raise and keep the impact factor above 2 . We have very good chances to achieve this goal, as the 5-year impact factor of the journal is already 2.003. Our middle and long term goal is to increase the journal's recognition to be on a level with the best journals in its field. Right now, eXPRESS Polymer Letters ranks at the end of the first third of all the journals of similar topics, but we would like it to rank in the top $10 \%$. This would require a longer time, as we are one of the youngest journals in this field, so it is a really outstanding result to be in the top third only after six years. The credit for this goes to the article topics that are in the forefront of the researchers' interest today. Tak-

\footnotetext{
${ }^{*}$ Corresponding author, e-mail: czigany@eik.bme.hu (c) BME-PT
}

ing a look back on the most popular and most cited articles of the past six years, we can conclude that the main topics are still the natural materials like biopolymers and biocomposites, (keywords include starch, wood, cellulose, chitosan, biodegradable, soybean oil), which is in accordance with the industry's expectations toward researchers. However, articles about nano materials also maintain their popularity (keywords include nanofibres, nanoparticles, nanotubes, nanocomposites, graphene), even though as these materials have failed to meet the high industrial expectations, their significance and number have dropped markedly. Apart from this, articles about structure-property relationships, optimization of technological parameters, preparation of new structural materials, or development of polymers with special characteristics are popular, too.

Based on all this, we look forward to the critical seventh year that we expect to bring continuous progress for the eXPRESS Polymer Letters. Finally, we are respectfully thankful for the professional work of our authors and referees, and in the name of the editor-in-chief, the international advisory board and the local editorial team, the editor wishes you a lot of success in year 2013. Sincerely yours,

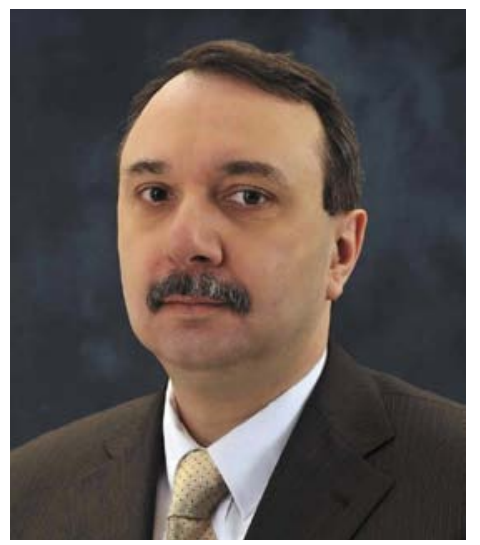

Prof. Dr. Tibor Czigány, editor 